\title{
Comité de Tuberculosis. Región Metropolitana. 2009. Selección de temas
}

\author{
CARLOS PEÑA M.*, CHRISTIAN GARCÍA C.** y LAURA CHIHUAILAF Q.***
}

Tuberculosis committee. Región Metropolitana. 2009.

Selection of subjects

\section{SITUACIÓN EPIDEMIOLÓGICA DE LA REGIÓN METROPOLITANA}

La SEREMI Metropolitana presentó la distribución comunal de las tasas de tuberculosis por 100.000 habitantes en todas sus formas del año 2008. Las comunas con mayores tasas en cada Servicio de Salud (SS) fueron: Independencia y Recoleta en SS Norte (Figura 1.1), Macul y Providencia en SS Oriente (Figura 2.1), San Ramón y San José de Maipo en SS Suroriente (Figura 3.1), Santiago y Estación Central en SS Central (Figura 4.1), Renca y Cerro Navia en SS Occidente (Figura 5.1) y Lo Espejo en SS Sur (Figura 6.1).

Además, se presentó la casuística de notificaciones acumuladas durante el primer semestre de 2009, que corresponde a 524 casos, de los cuales 338 son hombres $(65 \%)$ y 98 son adultos mayores (19\%). Al proyectar la tasa al resto del año se alcanzan cifras levemente superiores a las del año 2008. Los servicios de salud en los que aumentaron más los casos son el SS Norte, Sur, Suroriente y Central (Tabla 1.1). En la distribu- ción de género se aprecia el doble de hombres con respecto a las mujeres (Tabla 2.1) y según grupo etario, las tasas son mayores en adulto mayor (Tabla 3.1).

En relación a la importancia de los grupos vulnerables, se identificaron 147 casos $(36,7 \%)$ con algún factor de riesgo entre enero y julio de 2009 (Tabla 4.1). Dentro de los grupos vulnerables identificados el más frecuente es el adulto mayor ( $31 \%$ de los casos con factores de riesgo), seguido por los pacientes VIH/SIDA (20\%) y los inmigrantes (16\%) (Figura 7.1).

En relación con los enfermos de tuberculosis fallecidos, que alcanzan a 11 casos en el primer semestre de 2009, 5 de ellos corresponden al SS Norte. En 3 de los fallecidos existía el antecedente de infección VIH y 10 de ellos era vírgenes a tratamiento. Además 7 de los fallecidos eran adultos mayores. La tuberculosis pulmonar fue la causa del deceso en 8 casos y la meníngea en 3 .

* Encargado Programa Tuberculosis Servicio de Salud Metropolitano Central.

** Encargado Nacional Programa Tuberculosis de Chile.

***Departamento Salud Pública y Planificación Sanitaria. SEREMI Región Metropolitana. 

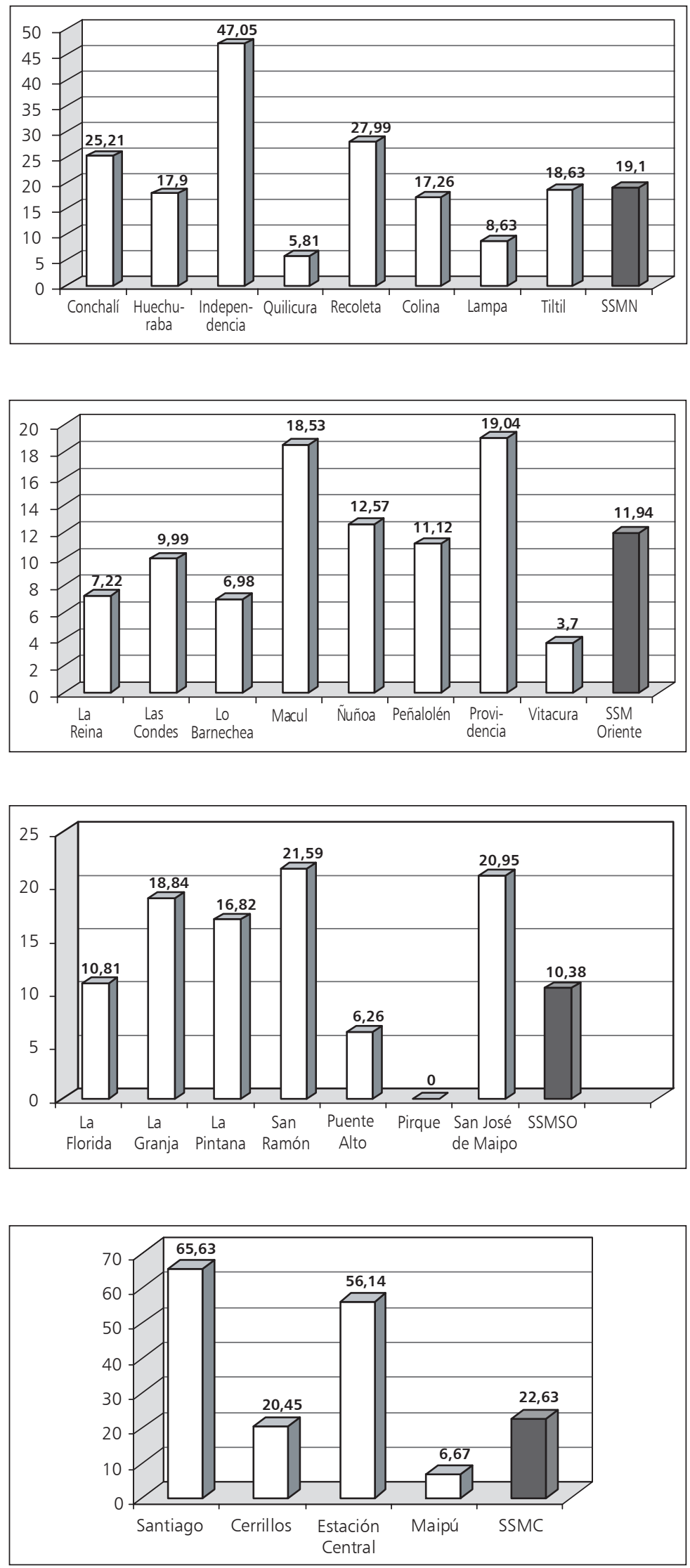

Figura 1.1. Tasas de tuberculosis por 100.000 habitantes en comunas del SS Norte.

Figura 2.1. Tasas de tuberculosis en comunas del SS Oriente.

Figura 3.1. Tasas de tuberculosis en comunas del SS Suroriente.

Figura 4.1. Tasas de tuberculosis en comunas del SS Central. 


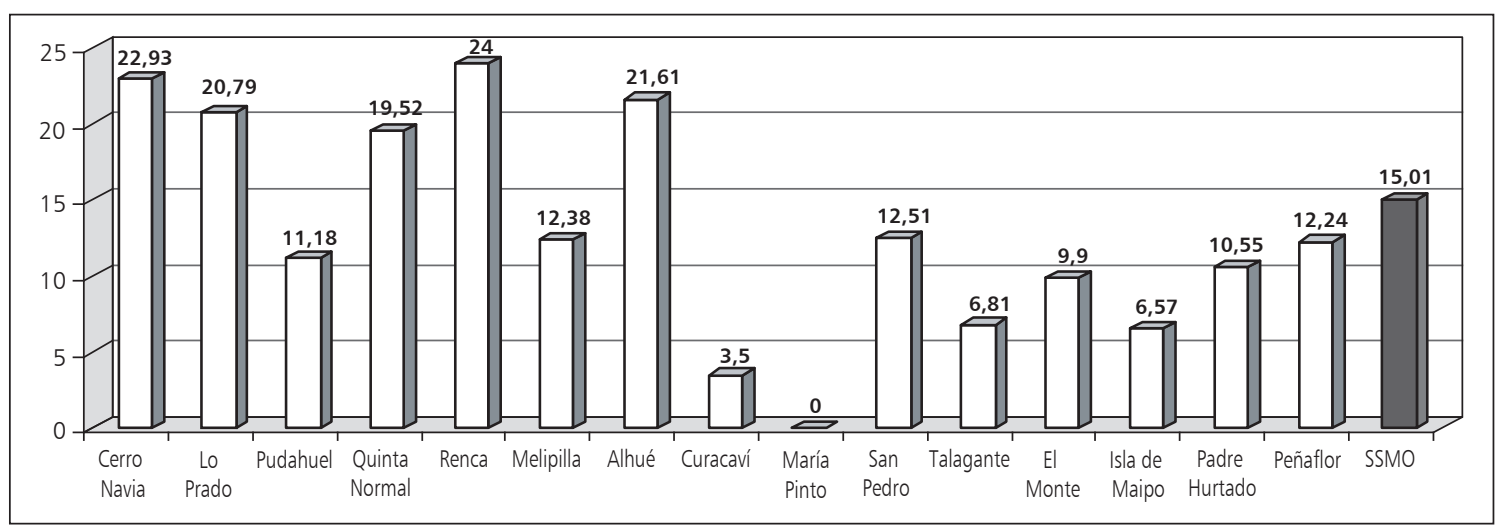

Figura 5.1. Tasas de tuberculosis por 100.000 habitantes en comunas del SS Occidente.

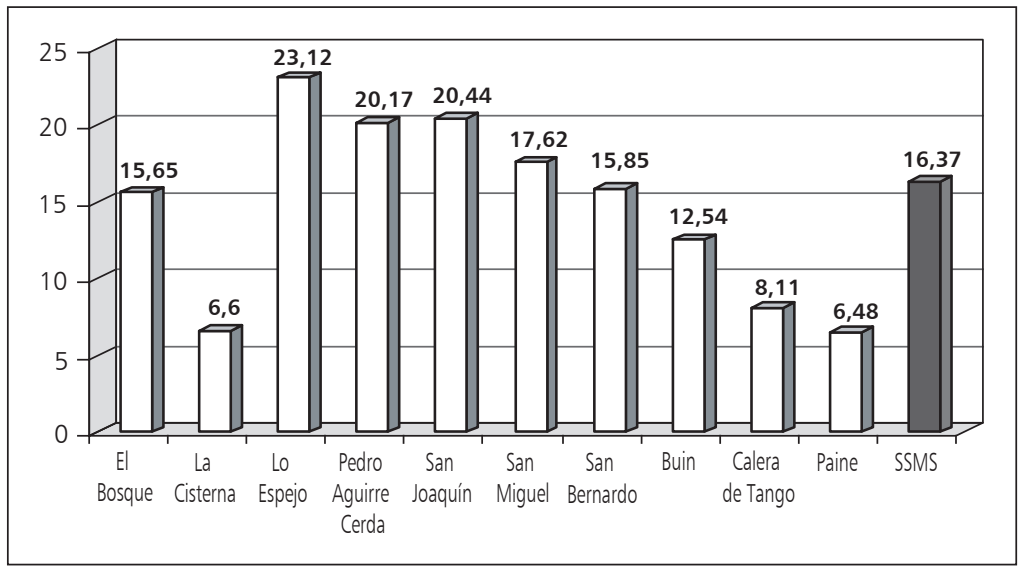

Figura 6.1. Tasas de tuberculosis en comunas del SS Sur.

Tabla 1.1. Tasa de tuberculosis por 100.000 habitantes en todas las localizaciones. RM. 2002-2009 (Proyectado)

\begin{tabular}{|lcccccccc|}
\hline Servicio de salud & $\mathbf{2 0 0 2}$ & $\mathbf{2 0 0 3}$ & $\mathbf{2 0 0 4}$ & $\mathbf{2 0 0 5}$ & $\mathbf{2 0 0 6}$ & $\mathbf{2 0 0 7}$ & $\mathbf{2 0 0 8}$ & $\mathbf{2 0 0 9}$ \\
SSMS & 21,8 & 19 & 22,1 & 20,9 & 19,6 & 17,6 & 19,27 & 21,8 \\
SSMSO & 12,2 & 11,9 & 10,2 & 9,7 & 9,5 & 8,4 & 8,59 & 9,72 \\
SSMO & 12,2 & 9,7 & 8,9 & 8,8 & 7,5 & 7,5 & 18,62 & 17,52 \\
SSMOCC & 19,9 & 19,5 & 17,8 & 19,8 & 20,6 & 13,2 & 15,28 & 6,56 \\
SSMN & 18,7 & 15,4 & 18,4 & 13,2 & 18 & 19,2 & 19,43 & 23,32 \\
SSMC & 19,6 & 15,4 & 20,1 & 18,6 & 17,6 & 18,5 & 15,66 & 20,26 \\
Total RM & 17,1 & 16,1 & 15,6 & 15,1 & 14,9 & 13,6 & 15,33 & 15,68 \\
\hline
\end{tabular}

SSM: Servicio de Salud Metopolitano. S: sur; SO: sur-oriente; O: oriente; OCC: occidente; N: norte; C: central; RM: Región Metropolitana. 
Tabla 2.1. Tasa de tuberculosis por 100.000 habitantes en todas las localizaciones según género.

RM. 2002-2009 (Proyectado)

\begin{tabular}{|c|c|c|c|c|}
\hline \multirow[b]{2}{*}{ Año } & \multicolumn{2}{|c|}{ Femenino } & \multicolumn{2}{|c|}{ Masculino } \\
\hline & $\begin{array}{c}n \text { casos } \\
\text { TBC TF }\end{array}$ & Tasa & $\begin{array}{c}n \text { casos } \\
\text { TBC TF }\end{array}$ & Tasa \\
\hline 2002 & 425 & 13,3 & 645 & 21,2 \\
\hline 2003 & 373 & 11,4 & 657 & 21,1 \\
\hline 2004 & 339 & 10,2 & 670 & 21,3 \\
\hline 2005 & 367 & 11 & 624 & 19,6 \\
\hline 2006 & 365 & 10,8 & 607 & 18,8 \\
\hline 2007 & 289 & 8,4 & 529 & 16 \\
\hline 2008 & 347 & 10,14 & 690 & 21,18 \\
\hline 2009 & 141 & 8,2 & 260 & 15,96 \\
\hline
\end{tabular}

$\mathrm{TBC} \mathrm{TF}=$ Tuberculosis todas las localizaciones.

Tabla 3.1. Tasa de tuberculosis por 100.000 habitantes en todas las localizaciones según grupos de edad. RM. 2002-2009 (Proyectado)

\begin{tabular}{|lrrrrrrrr|}
\hline & $\mathbf{2 0 0 2}$ & $\mathbf{2 0 0 3}$ & $\mathbf{2 0 0 4}$ & $\mathbf{2 0 0 5}$ & $\mathbf{2 0 0 6}$ & $\mathbf{2 0 0 7}$ & $\mathbf{2 0 0 8}$ & $\mathbf{2 0 0 9}$ \\
\hline$<15$ años & 2,1 & 0,9 & 0,7 & 0,9 & 1,7 & 0,8 & 1,25 & 0,5 \\
$15-64$ años & 19,8 & 19,3 & 18,5 & 16,2 & 16,8 & 14,5 & 24,44 & 21,95 \\
$>$ 64 años & 43,6 & 39,5 & 38,7 & 44 & 38 & 26 & 40 & 28,66 \\
\hline
\end{tabular}

Tabla 4.1. Proporción de grupos vulnerables

\begin{tabular}{|lcc|}
\hline Grupos & $\begin{array}{c}\text { TBC TF } \\
\text { n casos }\end{array}$ & $\begin{array}{c}\text { TBC TF } \\
\text { \% }\end{array}$ \\
Coinfección VIH & 35 & 8,7 \\
Inmigrantes & 27 & 6,7 \\
Alcoholismo & 18 & 4,5 \\
Contacto TBC & 16 & 3,9 \\
Adultos mayores & 54 & 13,5 \\
Patologías asociadas & 22 & 5,5 \\
\hline Total & 147 & 36,7 \\
\hline
\end{tabular}

$\mathrm{TBC} \mathrm{TF}=$ Tuberculosis en todas sus formas.

$\mathrm{VIH}=$ Virus inmunodeficiencia humana.

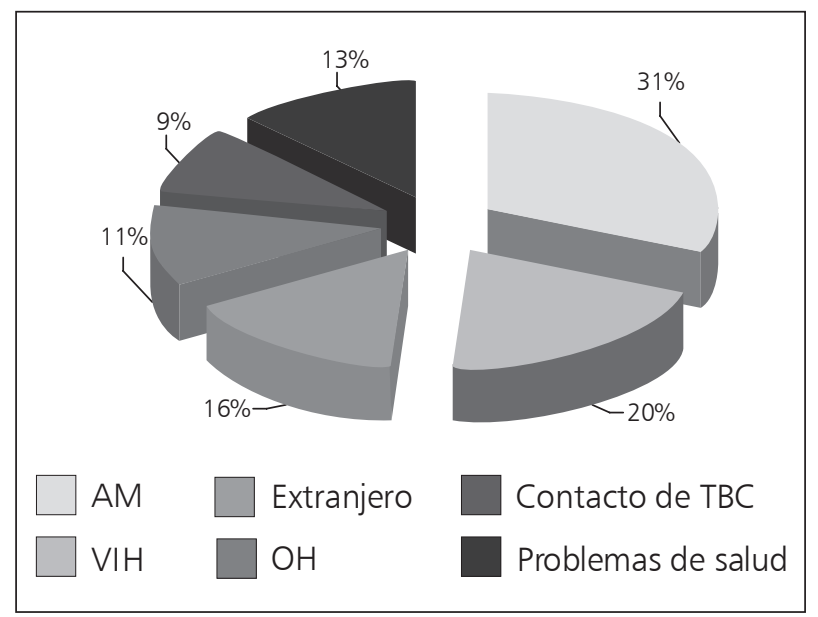

Figura 7.1. Distribución grupos vulnerables. $A M=$ adultos mayores; $\mathrm{OH}=$ alcoholismo; $\mathrm{SIDA}=$ Síndrome de inmunodeficiencia adquirida. 


\section{MESA DE TRABAJO INTERSECTORIAL PARA EL CONTROL DE LA TUBERCULOSIS}

En relación a la necesidad de proseguir con las metas epidemiológicas (focalización de la pesquisa de casos bacilíferos) y operacionales (asegurar los resultados del tratamiento a través de la disminución de los abandonos), del Programa Nacional de Control de la Tuberculosis (PNT), es necesario contar con la participación de otros sectores de la población. Con este propósito se iniciaron los contactos con algunas de las fuerzas vivas de la comunidad, a través de la creación de una "Mesa de Trabajo Intersectorial".

Dentro de los convocados a las primeras reuniones, según este plan iniciado en la Región Metropolitana, se encuentra el "sector privado" representado por profesionales referentes para el PNT en las clínicas y hospitales privados de la región, la Asociación de Damas Peruanas y el Consulado del Perú, personal de salud de los Centros de Reclusión (cárceles) y Directivos de la Cruz Roja, entre otros. La participación de las organizaciones comunitarias se encuentra dentro de la estrategia "Alto a la Tuberculosis" (StopTB), patrocinada por la OMS.

Con la colaboración de estas organizaciones, esperamos mejorar el rendimiento del programa de localización de casos y conseguir un mejor control del tratamiento de pacientes inmigrantes, en situación de calle, reclusos y del sector privado.

\section{PROYECTO DE INVESTIGACIÓN SOBRE TUBERCULOSIS Y POBREZA}

Esta investigación prospectiva, efectuada por los Drs. Carlos Peña M., Manuel Zúñiga G., Thomas R. Navin y la enfermera Sra. Zulema Torres G., en la Región Metropolitana durante los últimos 3 años, contó con el patrocinio del "Centers of Disease Control" (CDC) de Atlanta, USA. Sus resultados aún no han sido publicados in extenso. La investigación propone como objetivo primario determinar si los pacientes con tuberculosis pulmonar bacteriológicamente demostrada, en condiciones de pobreza, tienen un menor éxito terapéutico y, como objetivos secundarios, medir la magnitud de la situación de pobreza en los enfermos con tuberculosis de cualquier locali- zación y evaluar los efectos de la edad, género y lugar de residencia sobre los resultados del tratamiento.

Mediante una entrevista social se logró conocer la previsión y niveles de ingreso familiar per cápita en 129 pacientes con tuberculosis de la Región Metropolitana (Tabla 1.3). El 49\% de los casos correspondieron a FONASA A y el $30 \%$ a FONASA B (Figura 1.3).

Se encontró un ingreso per cápita promedio de \$ 66.689 (2005). En el 39\% de los enfermos con tuberculosis existía pobreza o indigencia (Figura 2.3), con un ingreso per cápita inferior a \$ 43.712, según MIDEPLAN (2003). El 78\% de

Tabla 1.3. Distribución de previsión de salud en 129 enfermos con tuberculosis de la Región Metropolitana

\begin{tabular}{|lcccccc|}
\hline & Fonasa A & Fonasa B & Fonasa C & Fonasa D & Privados & Total \\
\hline Hombres & 38 & 24 & 6 & 8 & 4 & 80 \\
Mujeres & 25 & 15 & 4 & 3 & 2 & 49 \\
Total & 63 & 39 & 10 & 11 & 6 & 129 \\
\hline
\end{tabular}

Fonasa: Fondo nacional de salud por nivel de ingresos económicos siendo A al más bajo y D el más alto. Privados: sistema de salud privado. 
ellos pertenecían a FONASA A. La indigencia (ingreso per cápita menor de \$21.856) es más frecuente en hombres.

Los pacientes de FONASA A tienen el menor ingreso per cápita de todas las categorías previsionales, con un promedio de $\$ 42.439$, similar en hombres y mujeres.

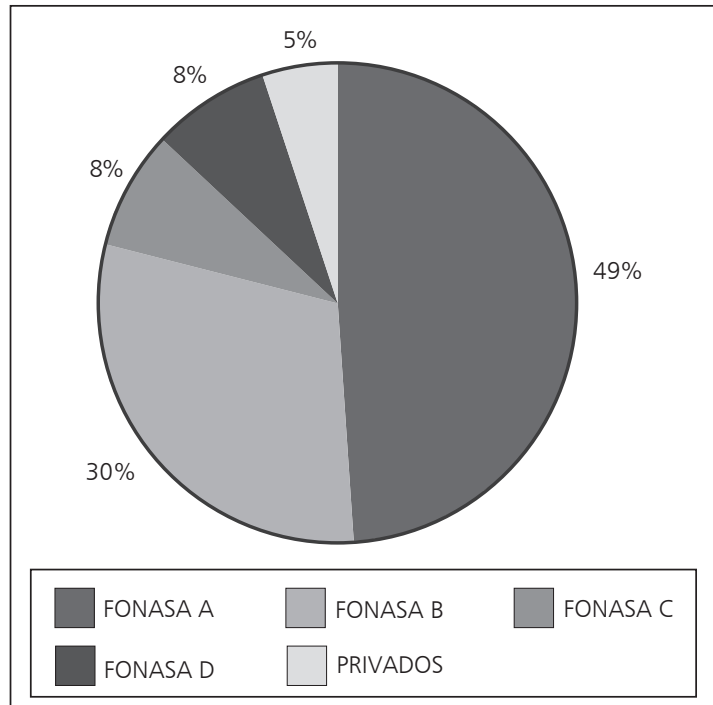

Figura 1.3. Proporción de categorías de previsión de salud en 129 enfermos con tuberculosis de la Región Metropolitana.

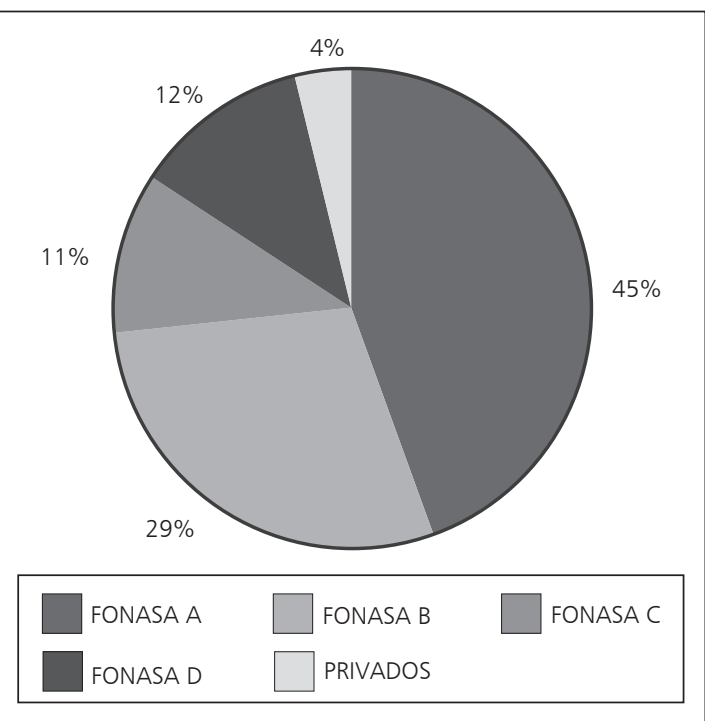

Figura 3.3. Proporción de casos de tuberculosis pulmonar con baciloscopia $(+)$ según categoría de previsión de salud.
El seguimiento de los resultados en 475 casos de tuberculosis pulmonar con baciloscopias positivas (Figura 3.3) muestra que el $45 \%$ de los casos pertenecen a FONASA A y el $29 \%$ a FONASA B. Esto refleja que la tuberculosis es más frecuente en los niveles previsionales de menores ingresos.

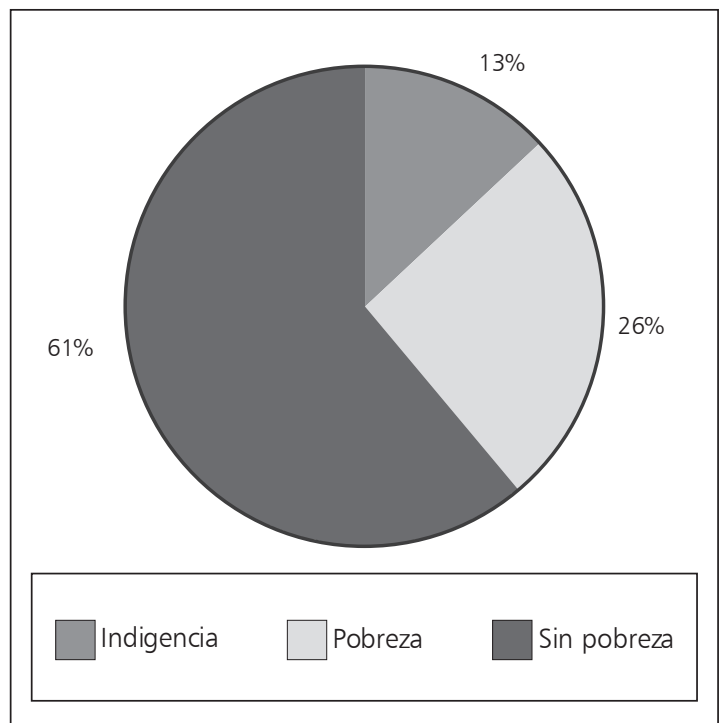

Figura 2.3. Proporción de casos según grado de pobreza en 475 casos de tuberculosis pulmonar con baciloscopia $(+)$.

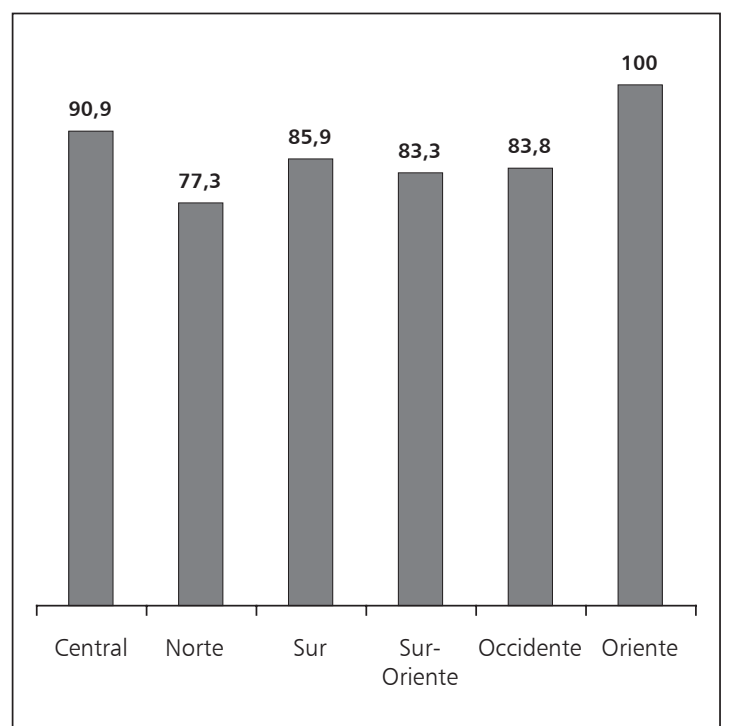

Figura 4.3. Porcentaje de curación casos de tuberculosis pulmonar según servicio de salud. 


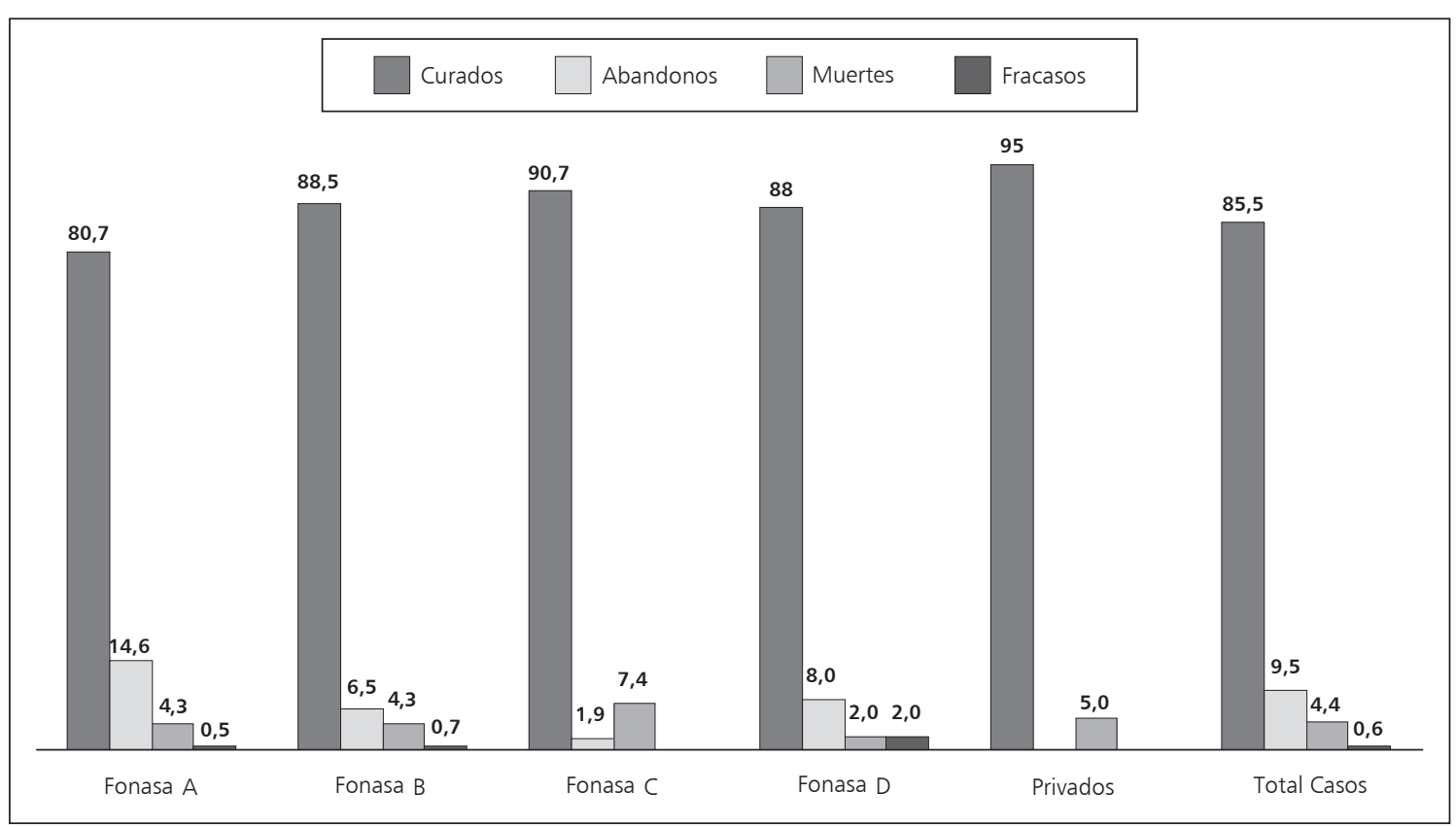

Figura 5.3. Porcentajes de curación según categoría previsional de salud. En cada categoría la primera columna de izquierda a derecha representa el porcentaje de curación, la segunda el porcentaje de abandono de tratamiento, la tercera el porcentaje de muertes y la cuarta columna el porcentaje de fracasos de tratamiento.

Respecto a los resultados del tratamiento, aunque en promedio su eficacia $(85,5 \%$ de curaciones el año 2008), no resultó inferior al mínimo recomendado por la OMS (> 85\%), sólo el 50\% de los servicios alcanzó este mínimo (Figura 4.3). El menor éxito con una curación promedio de $80,7 \%$, se observó en pacientes de FONASA A (Figura 5.3).

La eficacia se ve afectada por el nivel de abandonos y este factor se relaciona con la edad del paciente. El 75,6\% de los abandonos ocurrió en menores de 45 años de edad, lo que probablemente refleja la condición de personas jóvenes con desempleo o salarios reducidos e inmigrantes. El abandono es mayor en FONASA A donde alcanzó un $14,6 \%$, lo que podría estar relacionado también con pobreza.

Estos estudios permitirán diseñar estrategias de apoyo socio-económico para revertir la menor expectativa de curación en enfermos tuberculosos en situación de pobreza. 